\title{
Common and Uncommon Sources of Growth in Asia Pacific ${ }^{1}$
}

\author{
Enzo Weber \\ Institut für Statistik und Ökonometrie, Freie Universität Berlin \\ Boltzmannstr. 20, 14195 Berlin, Germany \\ eweber@wiwiss.fu-berlin.de \\ phone: +49 30 838-55792 fax: +49 $30838-54142$
}

\begin{abstract}
This paper embarks to analyse the role of exports and investment supposed to be major sources of economic growth in Asia Pacific. Therefore at first, the cointegration properties of exports, capital formation and GDP are examined in vector error correction models (VECMs). The results confirm the crucial role of exports and investment in the Asian growth dynamics. In a second stage, the structural shocks are identified by short- and long-run restrictions. These shocks, as well as the corresponding dynamic responses, are then correlated across all sample countries to provide insight into the depth of regional coherence. At last, the identified trends are explained by various macroeconomic variables.

Keywords: Economic Growth, Structural VECM, Export, Investment, Asia Pacific JEL classification: O11, F15, C32
\end{abstract}

\footnotetext{
${ }^{1}$ This research was supported by the Deutsche Forschungsgemeinschaft through the CRC 649 "Economic Risk". I am grateful to Jürgen Wolters and Cordelia Thielitz for their support. Of course, all remaining errors are my own.
} 


\section{Introduction}

Since the 1970s, the Asian Pacific region has witnessed an incomparable economic upswing, which has later on been called the "Asian miracle". Countries, which had traditionally relied on policies such as import substitution and national subsistence switched to an enduring export-orientated strategy. This change coincided with the take-off of foreign direct investments mostly conducted by multinational firms intending to tap new markets and striving for profitability increases. In addition, high domestic savings enabling continuous investment were backing the sustained development. Nevertheless, these vibrant dynamics are not common to all the region's nations, thus leaving several economies in a pre-take-off state of relative stagnation. The appearance of severe crises, most recently in 1997/98, additionally harmed the image of self-enduring growth.

The exceptional development dynamics of the last decades are inconceivable without the sustained influence of exports and investment. The close connection of those two growth drivers with technological progress, acquisition of knowledge and market liberalisation set up two major steering forces behind the remarkable economic success, drawing attention of several strands of literature: The role of exports in the Asian economies has been analysed for example by Krueger (1985). Nelson and Pack (1999) provide a critical review on the approaches favouring a key function of capital accumulation in the Asian growth processes. The literature about identifying structural shocks as driving forces is mainly based on the theory of optimal currency areas and was initially influenced by Bayoumi and Eichengreen (1994). These authors specified output and inflation vector autoregressive models in order to isolate one persistent supply and one transitory demand shock, but did not deduce restrictions from the presence of common stochastic trends.

Given the above considerations, I believe it is worthwhile to pursue the following key questions in the present analysis: Is it possible to detect export and investment trends driving the GDP growth dynamics? Which roles can be assigned to each of these trends? Is there any evidence for regional coherence in the sense of similarity between the structural innovations, and what are special characteristics for example of the "Asian tigers"? Finally, which are determinants of the identified trends?

This paper approaches the outlined issues in the context of an empirical time series analysis, which will be proceeded on an aggregated macro-level. The examination works with cointegration restrictions, which are imposed on reduced form VECMs. In this, I explicitly consider the recent structural breaks in the Asian economies. In the second step, longand short-run restrictions are deduced from the model properties and economic consider- 
ations. In the identified model structure, the growth effects are examined using impulse responses and variance decompositions. Additionally, the structural shocks are compared among the nations and explained by relevant macroeconomic variables.

In order to knit my research to a theoretical line, I start out to present the basic economic concepts of export and investment dynamics, which underlie my empirical modelling. Section 3 introduces the econometric techniques with emphasis on cointegration and identification. Afterwards, the results of the reduced form and structural models are presented and analysed in section 4 . In the end, the summary gives a concluding overview.

\section{Economic Foundation}

Since the seminal work of Solow (1956), literature on growth has mostly concentrated on the determination of steady state paths. Therein, the neoclassical approach stresses, that due to diminishing marginal returns in the aggregate production function deviations from the equilibrium growth rate can only be transitory. Especially, the development of capital accumulation has no long-run effect on growth rates, which are determined by exogenous technological progress. Furthermore, the theory implies convergence of per capita income levels between nations, since less developed countries should achieve higher growth rates. Of course, in case of structural economic parameters differing across countries, convergence would have to be conditioned on these determinants.

As a reaction, the endogenous growth theory, with its origins in Romer (1986) and Lucas (1988), has been developed. Essentially, model-inherent mechanisms prevent the growth rates from falling quasi automatically caused by diminishing marginal returns. The most prominent examples are endogenous technological change and human capital augmentation. As a consequence, the hypothesis of necessary convergence to an exogenously determined steady state path cannot be maintained.

The outstanding development the newly industrialised countries in Asia Pacific have taken in the last decades casts doubt on the implications of the neoclassical approach. However, in the empirical time series context a long-run link between stationary growth rates and non-stationary real investment, as predicted by endogenous growth models, seems rather problematic (see Jones 1995). In this paper, I do not test the validity of certain theories, but focus on the sources of the partly rapid expansion of income levels in the Asian Pacific region, notwithstanding the debate on theoretical steady state properties. 
In several strands of literature, above all exports and investment have been assumed to be main sources of the extraordinary Asian Pacific development. The corresponding empirical tests for the most part are based on the concept of Granger causality between measures of output and exports respectively investment (see e.g. Krishna, Ozyildirim and Swanson (1998), or Feasel, Kim and Smith (2001) for a combined analysis). Intending to find out the structural economic forces behind the "Asian miracle" and their regional coherence, apart from GDP I include both real capital formation and exports in structural cointegration models. In the following, major theoretical justifications for the important role of the chosen variables in growth processes are given.

First of all, both exports and investment are components of the aggregated demand and therefore have a direct influence on the GDP level. Even though, in an economic growth context it is supply side arguments, which are of decisive importance:

The role of investment is closely linked to the main arguments in growth theory: For the neoclassical part, factor endowment accumulation is the key variable for catching-up, even though representing only transitory processes. However, the endogenous approach assigns persistent effects to real investment, which generally stem from external effects (see Romer 1986 and Lucas 1988): For example, a higher capital accumulation could trigger further technological progress, resulting in higher productivity. Likewise, the idea of dynamic interaction between physical capital and human resources, comprising abilities, knowledge, experience and social institutions, directs to structural growth effects of investment which exceed pure moving along the production function. At last, the notion of embodied growth (Solow 1960), meaning that new capital goods are bearers of inherent technological progress, is of straightforward importance. For a debate on factor accumulation and technology as sources of Asian growth see Krugman (1994) and Rodrigo (2000), as well as the references therein.

Most approaches on export impacts origin in the theories of growth or development, as elaborated in Lewis (1980), Feder (1982), Helpman and Krugman (1985) and Krueger (1985). First of all, openness to trade is likely to increase the intensity of competition and set economic incentives, thus enhancing efficiency in production and causing sector reallocation. Contact to the world markets may trigger learning processes and generate knowledge about manufacturing processes, organisation, sales strategies and so on, even though this absorption might require some minimum level of development (e.g. Grossman and Helpman 1991). Furthermore, export strengthening could be a solution to the problem of growth constraints in case of foreign exchange restricting important imports or policy flexibility. At last, scale and specialisation effects are likely to occur as markets expand, 
so that for example problems of large minimum plant sizes are mitigated.

Of course, it should not be ignored, that in the reverse direction enhanced growth and competitiveness, possibly compared with domestic demand lagging behind, could lead as well to higher exports. In the same line, exports can rise in consequence of production augmented by real investment, and the other way round, capital formation might be encouraged in presence of a reliable foreign demand source and creditworthiness based on sound foreign accounts.

In the light of the forestanding arguments I will try to identify the common trends in exports (EXP), gross fixed capital formation (GCF) and gross domestic product (GDP) as generated by export and investment shocks. In this context, innovations with only transitory effects are likely to take the role of demand shocks.

\section{Methodological Proceeding}

\subsection{Reduced Form Models}

The basic data generating process in the econometric procedure is the VAR with lag length $q+1$

$$
y_{t}=c_{0}^{*}+c_{1}^{*} t+c_{2}^{*} b_{t}+c_{3}^{*} s_{t} t+c_{4} d_{t}+\sum_{i=1}^{q+1} A_{i}^{*} y_{t-i}+u_{t},
$$

where $y_{t}$ contains the $n$ endogenous variables, $A_{i}^{*}$ are $n \times n$ coefficient matrices and $u_{t}$ is an $n$-dimensional vector of white noise errors. The deterministic terms are constant, linear trend $(t)$, level breaks $\left(b_{t}\right)$ and trend shift $\left(s_{t}\right)$, as well as impulse and centred seasonal dummies $\left(d_{t}\right)$.

Before proceeding, assume that a unit root process is an acceptable description of the per capita GDP behaviour. According to Johansen (1995), the commonness of $n-r$ stochastic trends is reflected by a reduced rank of $A^{*}(1)$, with $A^{*}(L)=I_{n}-\sum_{i=1}^{q+1} A_{i}^{*} L^{i}$. Consequently, one can write $A^{*}(1)=-\alpha \beta^{\prime}$, where $\beta$ spans the space of the $r$ cointegrating vectors, and $\alpha$ contains the corresponding adjustment coefficients. Granger's representation theorem leads to the VECM 


$$
\Delta y_{t}=\alpha\left[\beta^{\prime} y_{t-1}+c_{0}+c_{1}(t-1)+c_{2} b_{t-1}+c_{3} s_{t-1}(t-1)\right]+c_{4} d_{t}+\sum_{i=1}^{q} A_{i} \Delta y_{t-i}+u_{t},
$$

with $A_{i}=-\sum_{j=i+1}^{q+1} A_{i}^{*}, i=1, \ldots, q$. This representation assumes that constant, trend and shifts are absorbed in the cointegrating relation; in case of empirically insignificant shifts, co-breaking allows to leave them out. Note that in (2) lagged intervention dummies, which condition the likelihood function in each subsample (defined by the break dates), as in Johansen et al. (2000), are not displayed for simplicity.

\subsection{Trend Analysis}

\subsubsection{Unit Root Tests}

The unit root behaviour of the non-breaking series is checked by the standard ADF test (see e.g. Dickey and Fuller 1979), with constant, trend and centred seasonal dummies included. Here, as well as in all subsequent models, the lag length is set following the usual information criteria (maximum lag 10) and autocorrelation tests. Simulated critical values for the null hypothesis of non-stationarity are taken from Davidson and MacKinnon (1993).

Various authors found, that the presence of structural breaks distorts the unit root test results, see i.e. Perron (1989). Certainly, there is no doubt, that such shifts have recently occurred in Asia Pacific. Here, I follow Saikkonen and Lütkepohl (2002), who propose first estimating the deterministic nuisance parameters and afterwards testing the residuals for non-stationarity. Accordingly, in the first step a GLS regression of the time series on constant, trend, dummies and shifts is run. As in the case of Asia Pacific, the dates, where shifts have occurred, are quite obvious, I assume the break points to be known a priori. In the second step, an ADF type test on the estimated residuals is performed. For critical values of the t-statistic and additional correction terms in the regression see Lanne et al. (2002).

\subsubsection{Cointegration Analysis}

Johansen $(1994,1995)$ provides a test for cointegration in the VECM in (2), Johansen et al. (2000) incorporate structural breaks. Their likelihood ratio trace test statistic for the null hypothesis of at most $r$ cointegrating relations is given by 


$$
\Lambda(r)=-T \sum_{i=r+1}^{n} \log \left(1-\hat{\lambda}_{i}\right)
$$

where $n$ is the number of endogenous variables and $T$ the number of observations. $\hat{\lambda}_{i}$ denotes the i-th largest squared sample canonical correlation between $\Delta y_{t}$ and the respective cointegrating relation, both corrected for the influence of the remaining regressors. Critical values are obtained by computing the response surfaces in Doornik (1998), or Trenkler (2004) in case of breaks.

\subsection{Identification}

From equation (2) it can be seen, that due to the lack of structure, the residuals in $u_{t}$ do not represent the economically interpretable innovations. The absence of explicit contemporaneous effects between the endogenous variables makes the error terms linear combinations of the underlying structural shocks. Formally, this is

$$
u_{t}=B e_{t},
$$

where $B$ contains the $n^{2}$ simultaneous impact coefficients, and $e_{t}$ represents the vector of structural disturbances. Normalising the variances of $e_{t}$ to one and assuming zero crosscorrelations yield $n(n+1) / 2$ different equations, still leaving $n(n-1) / 2$ restrictions to impose for the identification of the $B$ matrix. This is exactly the number of different instantaneous covariances.

From the VECM moving average representation (Johansen 1995) one gets the matrix of the long-run effects of the reduced form residuals $u_{t}$ :

$$
\Xi=\beta_{\perp}\left(\alpha_{\perp}^{\prime}\left(I_{n}-\sum_{i=1}^{q} A_{i}\right) \beta_{\perp}\right) \alpha_{\perp}^{\prime}
$$

with $\perp$ denoting the orthogonal complement (thus $\alpha^{\prime} \alpha_{\perp}=0$ ). Accordingly, the longrun matrix of $e_{t}$ results as $\Xi B$. From the cointegration properties it is known, that at most $r$ shocks have only transitory effects. Setting $r$ columns of $\Xi B$ to zero thus produces $r(n-r)$ independent restrictions, since $\Xi B$ has only the reduced rank of $n-r$. Therefore, identification is completed by $n(n-1) / 2-r(n-r)$ additional restrictions, of which $r(r-1) / 2$ must disentangle the transitory shocks (Gonzalo and Ng 2001). When the structural innovations are identified, they provide the base for impulse responses and forecast error variance decompositions (FEVD), which are estimated by the usual recursive calculations of the moving average representation. 


\section{Empirical Evidence}

\subsection{Data}

Country by country, this paper aims at identifying the growth impacts on GDP, which stem from exports and gross fixed capital formation. Including other variables, like human capital or FDI, might be desirable, but is prohibited by the lack of data. All the quarterly data have been taken from the EcoWin, IMF IFS, OECD and CEIC databases. The series have been transformed as follows: Per capita levels have been calculated by dividing by total population, which was linearly interpolated to gain quarterly data. The nominal data have been deflated to the 2002 level using the implicit price deflators for exports, capital formation and GDP, or, where not available, only the GDP deflator respectively the consumer price index. At last, the 2002 purchasing power parity conversion factors from the international comparison program of the World Bank have been employed to transform all series into US dollar. ${ }^{2}$ The calculated variables can be interpreted as the per quarter amount of dollars one would have needed in the USA in 2002, to reach the same level as in the respective country and period.

Figure 1 gives an overview of the time series from the respective starting points till the end of 2005. Several characteristics shall be emphasised: The sample can be split into the industrialised countries Australia, Hong Kong (Special Administrative Region of China), Japan, South Korea ("Korea" in the following), New Zealand, Singapore and Taiwan, and the more or less fast developing countries Indonesia, Malaysia, the Philippines and Thailand. In most cases, exports exceed investment in terms of magnitude. While Hong Kong, Malaysia and Singapore exhibit the largest export shares, the economies of Australia, Japan and Korea seem to rely more on domestic capital formation. Severe effects of the 1997/98 Asian crisis can be detected in the series of Hong Kong, Indonesia, Korea, Malaysia, Singapore and Thailand, countries known for having struggled the most by the time; in general, exports are less affected than GDP and GCF. The economic crisis in the early 1980s shows impacts mostly on Australia, Hong Kong, the Philippines and Singapore. ${ }^{3}$ Regarding the Oceanic countries Australia and New Zealand, there appears a growth weakness around 1992, which coincides with a general world economic downturn. In Japan the economic boom of the late 1980s is visible just as the long period of deflationary recession.

\footnotetext{
${ }^{2}$ For Taiwan, the factor has been calculated by a PPP update based on the 1990 relative price from Penn World Table.

${ }^{3}$ Of course, various series had not even begun in the early 80 s.
} 

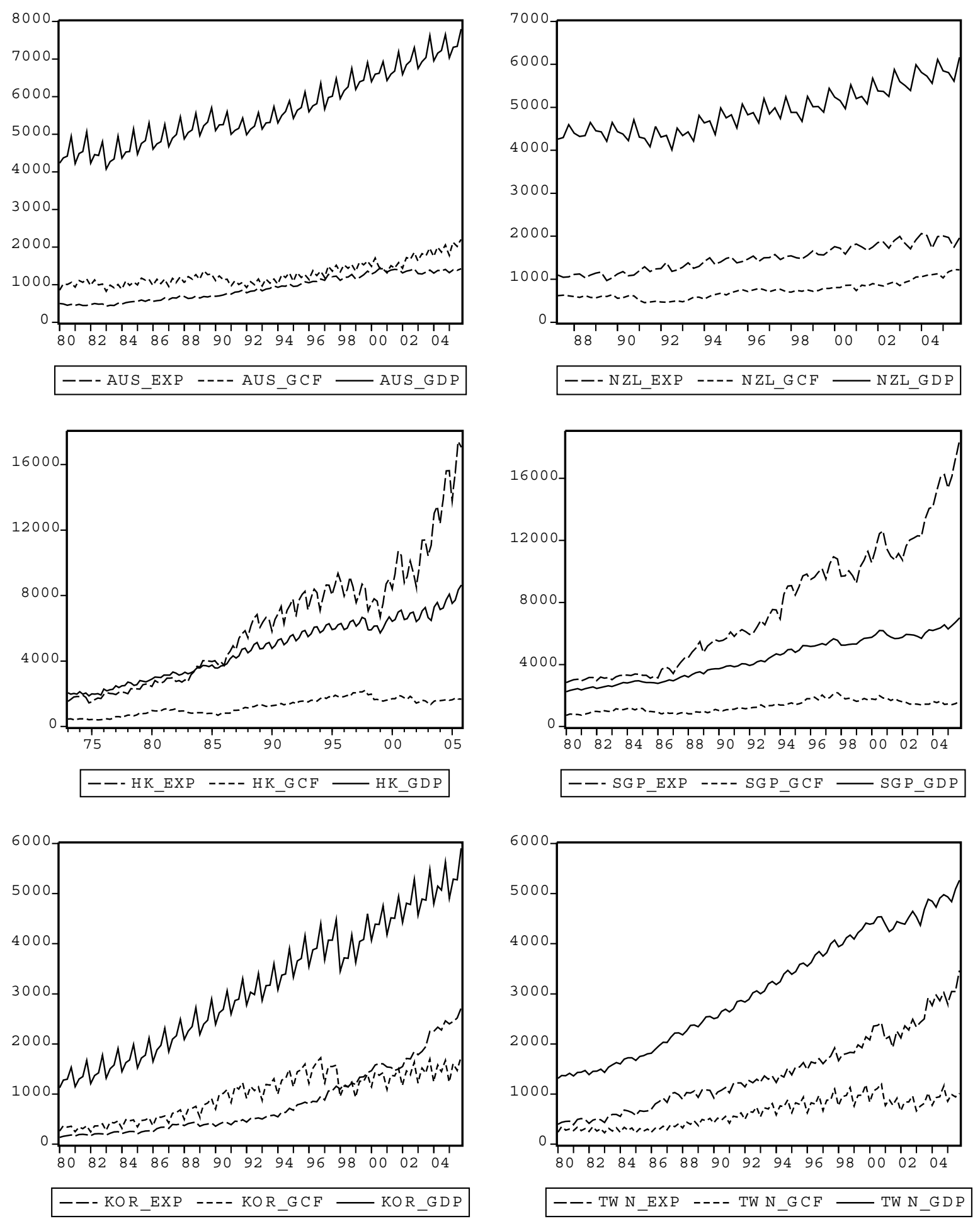

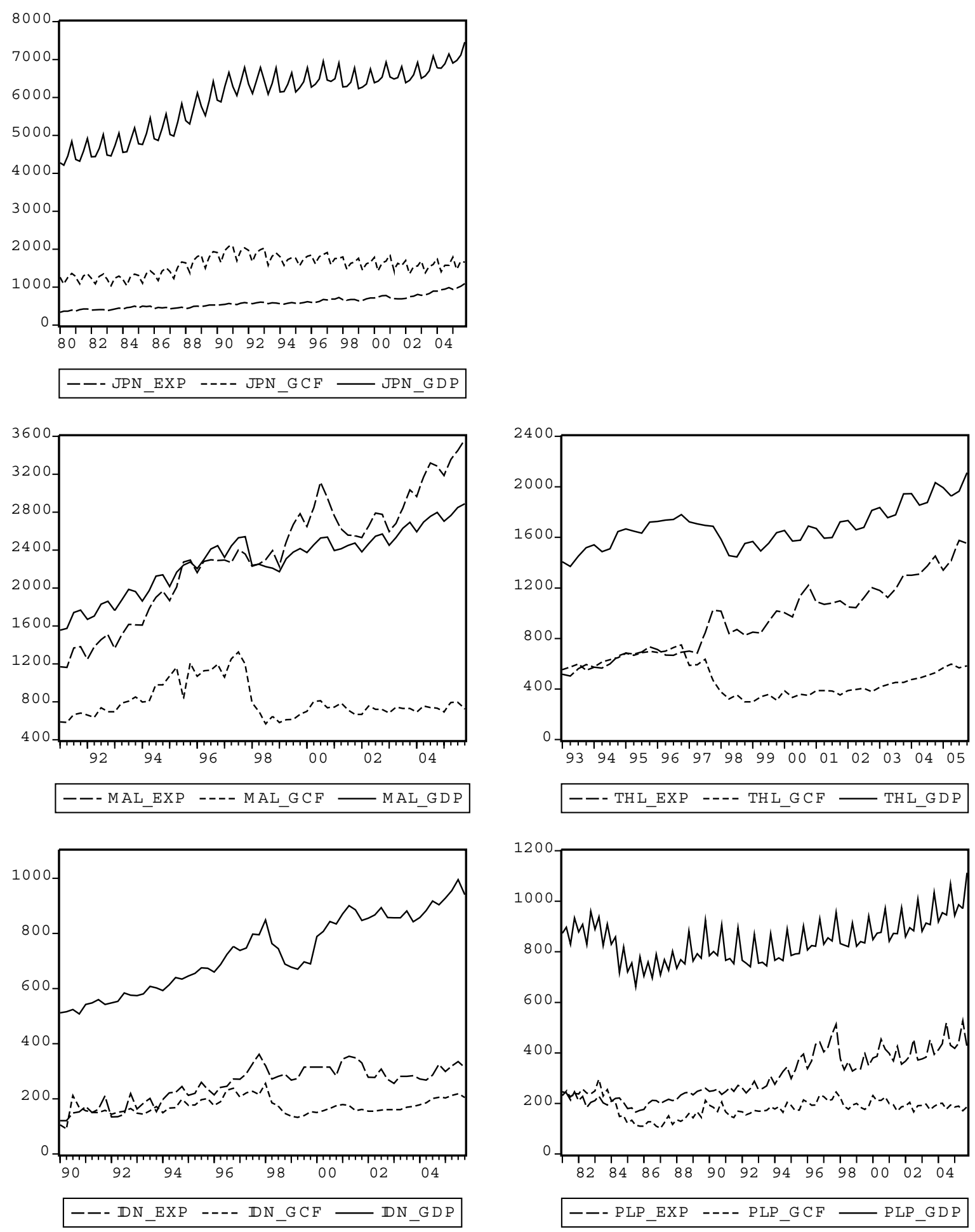

Figure 1: Exports, Gross Fixed Capital Formation and GDP (2002 p.c. PPP US \$) 
Finally, I provide formal tests for the presence of unit roots in the series: Appendix Table 12 displays the ADF statistics, or, where breaks have been considered, the Saikkonen and Lütkepohl (2002) statistics. In none of the cases, the null hypothesis of non-stationarity can be rejected at the $10 \%$ level. As additionally, the first differences are clearly stationary, I assume the series integrated of order one. All calculations in this paper have been done in JMulti 4.06 and EViews 5.0.

\subsection{Cointegration in National Models}

As I have established non-stationarity of exports, investment and GDP in all countries under consideration, I proceed with determining the number of common trends in each national system. For this reason, Table 1 displays the trace test statistics for the hypotheses of $r=0$ and $r=1$. The former can be rejected in all cases at least at the $5 \%$ level, however more than one cointegrating vector is not within reach.

\begin{tabular}{|c|c|c|c|c|c|c|c|c|c|c|c|}
\hline & AUS & HK & IDN & JPN & KOR & MAL & NZL & PLP & SGP & THL & TWN \\
\hline$H_{0}: r=0$ & $46.2^{*}$ & $77.2^{* *}$ & $33.7^{*}$ & $65.5^{*}$ & $52.3^{* *}$ & $48.6^{*}$ & $49.4^{*}$ & $53.0^{* *}$ & $46.5^{*}$ & $49.0^{* *}$ & $64.8^{* *}$ \\
\hline$H_{0}: r=1$ & 22.1 & 28.0 & 15.0 & 33.8 & 21.9 & 11.8 & 27.1 & 25.4 & 17.8 & 17.9 & 18.3 \\
\hline \multicolumn{8}{|c|}{$,{ }^{*}: H_{0}$ can be rejected at $1 \%$ respectively $5 \%$ significance level } \\
\hline
\end{tabular}

Table 1: Trace test statistics

Consequently, all VECMs are estimated including one error correction term. The models have been checked to pass the Jarque-Bera test and a Langrange multiplier test for serial correlation. ${ }^{4}$ The full specifications can be found in Appendix Table 13. Table 2 lists the cointegrating vectors for further interpretation: The relatively low standard errors indicate, that all variables are necessary elements in the respective equilibrium relations. ${ }^{5}$ Except for the Philippines, the GDP coefficient is the only one to carry a negative sign. This leads to the interpretation, that both EXP and GCF contain an idiosyncratic stochastic trend, and that these trends both drive the GDP growth. The high estimates for coefficients of Hong Kong, Malaysia, Singapore and Taiwan are attributable to their strong export performance.

\footnotetext{
${ }^{4}$ Due to the high number of models, I continue without presenting the details, which are available on request.

${ }^{5}$ Using different normalisations, this holds as well for the EXP parameters, and applying Wald tests to zero restrictions on the cointegrating vectors does not change the results. The export normalisation ist just to avoid small numbers and allows for estimating standard errors of the GDP parameters.
} 


\begin{tabular}{|c|c|c|c|c|c|c|c|c|c|c|c|}
\hline & AUS & HK & IDN & JPN & KOR & MAL & NZL & PLP & SGP & THL & TWN \\
\hline EXP & 1 & 1 & 1 & 1 & 1 & 1 & 1 & 1 & 1 & 1 & 1 \\
\hline GCF & 0.80 & 0.56 & 1.53 & 0.96 & 1.76 & 2.41 & 1.08 & -1.88 & 2.99 & 0.63 & 4.15 \\
& $(0.24)$ & $(0.29)$ & $(0.52)$ & $(0.23)$ & $(0.11)$ & $(0.36)$ & $(0.22)$ & $(0.36)$ & $(1.09)$ & $(0.06)$ & $(0.76)$ \\
\hline GDP & -0.80 & -3.64 & -0.45 & -0.88 & -2.11 & -4.90 & -1.03 & 0.49 & -9.04 & -0.94 & -3.44 \\
& $(0.13)$ & $(0.26)$ & $(0.10)$ & $(0.16)$ & $(0.17)$ & $(0.63)$ & $(0.13)$ & $(0.14)$ & $(1.19)$ & $(0.05)$ & $(0.67)$ \\
\hline \multicolumn{10}{|c|}{ standard errors in parentheses } \\
\hline
\end{tabular}

Table 2: Cointegrating vectors

Having defined the long-run relations, I now turn to the question of equilibrium adjustment, which is obviously a crucial one in the given growth context. As can be seen in Table 3, the reaction of GDP is always positive and clearly significant, lending support to the interpretation of export and investment trends driving economic growth. Exports do not adjust significantly (and correctly) but in Hong Kong, Japan and Thailand. For the two former, this might reflect the economic strength of their export-orientated sectors. The same countries surprisingly are those with significant and wrong-directed adjustment of GCF. A reverse pattern is found for Singapore, where GCF instead of EXP adjusts in line with the expectations. Of course, the theory of two stochastic trends belonging to the export and investment dynamics fits best to the cases, where these two variables are weakly exogenous. Otherwise, the interpretation is not as straightforward, but in presence of significant GDP adjustment still appealing.

As the only country, the Philippines deviate substantially from the established systematic functioning: While GDP enters the error correction term with a positive sign, it also reacts positively to equilibrium deviations. Qualitatively, this finding is not sensitive to different model specifications, estimation procedures and sample periods. The main reason is probably the very low GCF performance (see Figure 1), which makes it impossible to extract a positive impact on GDP.

\subsection{Structural VECMs}

In section 4.2, I have established two common trends each in all three-dimensional national models. To identify the underlying shocks, I first exploit the reduced rank properties by restricting the long-run impact of one shock to zero, thus interpreting it as demand innovation. As this provides two linearly independent restrictions, following the criterion from section 3.3, one more is needed for full identification. In the growth-orientated 


\begin{tabular}{|c|c|c|c|c|c|c|c|c|c|c|c|}
\hline & AUS & HK & IDN & JPN & KOR & MAL & NZL & PLP & SGP & THL & TWN \\
\hline EXP & 0.01 & -0.22 & -0.03 & -0.12 & 0.04 & -0.07 & -0.10 & -0.01 & 0.12 & -0.35 & 0.06 \\
& {$[0.74]$} & {$[-2.55]$} & {$[-1.03]$} & {$[-3.82]$} & {$[1.84]$} & {$[-1.15]$} & {$[-0.61]$} & {$[-0.46]$} & {$[4.93]$} & {$[-2.87]$} & {$[0.75]$} \\
\hline GCF & 0.01 & 0.07 & -0.04 & 0.24 & 0.04 & -0.07 & 0.09 & -0.01 & -0.02 & 0.45 & 0.05 \\
& {$[0.48]$} & {$[3.12]$} & {$[-1.60]$} & {$[2.84]$} & {$[1.32]$} & {$[-1.57]$} & {$[0.77]$} & {$[-0.28]$} & {$[-3.48]$} & {$[4.08]$} & {$[1.22]$} \\
\hline GDP & 0.35 & 0.13 & 0.12 & 0.53 & 0.23 & 0.09 & 0.82 & 0.12 & 0.03 & 0.31 & 0.12 \\
& {$[7.76]$} & {$[3.58]$} & {$[5.29]$} & {$[4.46]$} & {$[8.52]$} & {$[3.35]$} & {$[4.37]$} & {$[5.40]$} & {$[3.81]$} & {$[2.94]$} & {$[2.28]$} \\
\hline \multicolumn{10}{|c|}{ t-values in brackets } \\
\hline
\end{tabular}

Table 3: Adjustment parameters

analytical frame it would surely be inconsistent to impose further long-run constraints. Therefore, I adopt the most sensible assumption about contemporaneous impacts: Clearly, as components of GDP, both export and investment must have simultaneous effects on income, which are to be estimated. By the same token, it seems unreliable to restrict the contemporaneous reaction of GCF, because investment is normally seen as reacting quite quickly to news giving ground to profit expectations. Provided linear independence, it remains to constrain the contemporaneous impact of investment on exports to zero. This does not seem unfounded, because first, the settling process of new capital is typically characterised by delays, and secondly, exports depend at least in the short-run mainly on foreign influences. Furthermore, my models do generally exhibit the lowest residual cross-correlations between GCF and EXP, averaging to 0.18 .

Before proceeding, all insignificant parameters have been sequentially eliminated in order to enhance efficiency and to avoid disturbing the residuals, which shall form the series of structural shocks. The corresponding plots and the GDP impulse responses can be found in Appendix Figures 2 and 3. Table 4 includes key information about the structural longrun effects of export and investment shocks on GDP (measured as usually in 2002 per capita PPP US \$): The first rows contain the respective elements of the matrix $\Xi B$ with standard errors $^{6}$, and the last row shows the relations of FEVD long-run contributions to GDP. Basically all long-run coefficients are clearly significant and, with three exceptions, positive.

In most countries, the investment shocks bring about higher growth effects than the exports shocks. This is especially true for the matured economies of Japan, Korea and New Zealand and can as well be seen in the FEVD relations. Exceptions are Hong Kong, Singapore and Thailand, which are known to depend heavily on exports. The

\footnotetext{
${ }^{6}$ Standard errors are computed in a bootstrap procedure with 3.000 replications.
} 
negative GCF parameters for Hong Kong and Singapore are probably caused by the weak investment, above all in the phase of corporate and financial restructuring after the Asian crisis, contrasting with the enormous export performance (see as well Figure 1). The investment effects in the other industrialised economies exceed those in the developing countries, while this relation is partly reversed for exports. An appealing interpretation is, that economies with broad and deep industrial structures are less dependent on foreign impulses than countries with non-settled enclave-like technology sectors. Recalling the explanations from section 4.2, again the Philippine coefficients are at odds with the overall results, but are actually reflecting the economy's stagnating course of the last decades.

\begin{tabular}{|c|c|c|c|c|c|c|c|c|c|c|c|}
\hline & AUS & HK & IDN & JPN & KOR & MAL & NZL & PLP & SGP & THL & TWN \\
\hline EXP & 29.1 & 69.2 & 19.1 & 16.5 & 11.1 & 19.1 & 12.7 & 20.3 & 70.1 & 41.2 & 29.6 \\
& $(3.8)$ & $(13.4)$ & $(4.5)$ & $(8.8)$ & $(5.8)$ & $(4.3)$ & $(4.4)$ & $(9.1)$ & $(9.7)$ & $(9.7)$ & $(8.9)$ \\
\hline \multirow{2}{*}{ GCF } & 35.2 & -47.6 & 30.9 & 58.4 & 32.2 & 27.6 & 31.4 & -25.4 & -29.5 & 22.9 & 39.1 \\
& $(4.3)$ & $(12.3)$ & $(5.7)$ & $(15.8)$ & $(7.1)$ & $(3.6)$ & $(4.2)$ & $(10.6)$ & $(24.8)$ & $(7.0)$ & $(10.2)$ \\
\hline FEVD & $39 / 61$ & $71 / 29$ & $28 / 72$ & $8 / 92$ & $11 / 89$ & $33 / 67$ & $15 / 85$ & $39 / 61$ & $83 / 17$ & $76 / 24$ & $38 / 62$ \\
\hline \multicolumn{10}{c|}{ standard errors in parentheses } \\
\hline
\end{tabular}

Table 4: GDP long-run effects of structural export resp. investment unit shocks

Addressing the transitory demand shock, Table 5 provides the number of quarters with significant $^{7}$ impulse responses, as well as the accumulated long-run impulse responses (in 2002 per capita PPP US \$), which are reached at the very latest after about ten years. All measures keep within the bounds, which are implied by the interpretation of the identified shock as demand innovation. In Australia, the Philippines and Singapore these disturbances are most important and persistent.

\begin{tabular}{|l|c|c|c|c|c|c|c|c|c|c|c|}
\hline & AUS & HK & IDN & JPN & KOR & MAL & NZL & PLP & SGP & THL & TWN \\
\hline Duration (quarters) & 26 & 5 & 19 & 2 & 5 & 2 & 5 & 23 & 9 & 12 & 6 \\
Accumul.Responses & 244.9 & 1.9 & 59.5 & 109.2 & 80.4 & 27.3 & 47.3 & 249.1 & 337.3 & 167.6 & 56.3 \\
\hline
\end{tabular}

Table 5: GDP effects of structural demand unit shocks

\footnotetext{
${ }^{7}$ Significance is assessed by bootstrapping $95 \%$ Hall confidence intervals (see Hall 1992) with 3.000 replications.
} 


\subsection{Regional Coherence}

Table 6, 7 and 8 contain the cross-country correlations among the structural shocks in the lower left and among the impulse responses in the upper right triangles. The former give an impression of the coherence of structural innovations the countries are subject to. The latter then provide information, on which degree the shocks are processed symmetrically within the different economies. The impulse responses have been calculated for the first 30 quarters, capturing all relevant developments. Varying the end point has only negligible effects.

Evidently, the strongest correlations exist between the export innovations (mean=0.11): The main cluster consists of Hong Kong, Japan, Malaysia, Korea, Taiwan and Thailand, among which the bulk of correlations is significantly positive (mean=0.25). This definition roughly corresponds to the group of newly industrialised "Asian tigers", even though Singapore does not significantly correlate but with Taiwan. These connections could for example be explained by the development of transnational production and trade networks (see e.g. Kimura 2006) as well as common dependences on foreign demand. Another cluster could possibly comprise Australia, Indonesia and the Philippines. However, the impulse responses (mean=0.14) are most in line within the group of Australia, Indonesia, Malaysia, the Philippines, Singapore and Thailand (mean=0.86), Korea might be added. While this unites all less developed countries, the negative correlations including Hong Kong and Japan are a product of high impact multipliers going down in the following periods.

Among the investment shocks, evidence for coherence is weakest (mean=0.04). Apart from several correlations often involving Malaysia, no significance can be detected. Nevertheless, the reactions to GCF shocks (mean=0.04) follow a fairly symmetric course: Only Hong Kong, Singapore and the Philippines, the three countries, which are subject to negative long-run effects, deviate substantially from the normal adjustment pattern; with a mean of 0.71 , correlations are highest among Australia, Indonesia, Japan, Malaysia, Thailand and Taiwan.

The demand shock correlations average only to 0.04, but evidently, many negative values belong to developing countries. Indeed, one cluster might be found containing the industrialised nations (mean $=0.16$, without Singapore). In this, it should be considered, that my models include no nominal variables, which are normally seen as predestined for identifying structural demand innovations (e.g. Bayoumi and Eichengreen 1994). The responses to the transitory shocks are highly coherent, resulting in a mean correlation 


\begin{tabular}{|c|c|c|c|c|c|c|c|c|c|c|c|}
\hline & AUS & HK & IDN & JPN & KOR & MAL & NZL & PLP & SGP & THL & TWN \\
\hline AUS & $\times$ & -0.29 & $0.99^{* *}$ & $-0.91^{* *}$ & $0.41^{* *}$ & $0.73^{* *}$ & $-0.34^{*}$ & $0.93^{* *}$ & $0.93^{* *}$ & $0.99^{* *}$ & 0.06 \\
\hline HK & $0.17^{*}$ & $\times$ & -0.26 & $0.45^{* *}$ & $-0.33^{*}$ & -0.15 & -0.12 & $-0.34^{*}$ & -0.08 & -0.26 & -0.13 \\
\hline IDN & $0.27^{* *}$ & -0.15 & $\times$ & $-0.88^{* *}$ & $0.38^{* *}$ & $0.75^{* *}$ & -0.30 & $0.91^{* *}$ & $0.97^{* *}$ & $1.00^{* *}$ & 0.04 \\
\hline JPN & 0.08 & $0.25^{* *}$ & -0.06 & $\times$ & $-0.38^{* *}$ & $-0.68^{* *}$ & $0.46^{* *}$ & $-0.79^{* *}$ & $-0.89^{* *}$ & $-0.88^{* *}$ & -0.08 \\
\hline KOR & 0.01 & $0.19^{*}$ & -0.12 & $0.24^{* *}$ & $\times$ & -0.07 & -0.06 & $0.55^{* *}$ & 0.37 & $0.38^{* *}$ & 0.03 \\
\hline MAL & $0.29^{* *}$ & $0.41^{* *}$ & 0.00 & $0.36^{* *}$ & $0.19^{*}$ & $\times$ & $-0.35^{*}$ & $0.47^{* *}$ & $0.83^{* *}$ & $0.74^{* *}$ & $0.31^{*}$ \\
\hline NZL & 0.11 & 0.13 & 0.01 & -0.11 & 0.12 & -0.02 & $\times$ & -0.14 & $-0.31^{*}$ & -0.29 & -0.20 \\
\hline PLP & 0.16 & $0.17^{*}$ & $0.24^{*}$ & 0.13 & -0.00 & 0.10 & 0.13 & $\times$ & $0.81^{* *}$ & $0.91^{* *}$ & -0.09 \\
\hline SGP & 0.12 & 0.08 & -0.10 & 0.15 & -0.09 & 0.08 & $-0.22^{*}$ & 0.08 & $\times$ & $0.97^{* *}$ & 0.00 \\
\hline THL & 0.07 & $0.45^{* *}$ & 0.13 & 0.19 & 0.05 & $0.32^{* *}$ & 0.16 & 0.20 & 0.05 & $\times$ & 0.03 \\
\hline TWN & -0.07 & $0.28^{* *}$ & -0.21 & $0.22^{* *}$ & 0.10 & $0.24^{* *}$ & -0.05 & 0.11 & $0.20^{* *}$ & $0.23^{*}$ & $\times$ \\
\hline & \multicolumn{8}{c|}{${ }^{* *}{ }^{*}:$ significant at $5 \%$ respectively $10 \%$ level } & & \\
\hline
\end{tabular}

Table 6: Correlations among export shocks (lower left) and responses (upper right)

\begin{tabular}{|c|c|c|c|c|c|c|c|c|c|c|c|}
\hline & AUS & HK & IDN & JPN & KOR & MAL & NZL & PLP & SGP & THL & TWN \\
\hline AUS & $\times$ & $-0.55^{* *}$ & $0.62^{* *}$ & $0.50^{* *}$ & 0.17 & $0.51^{* *}$ & 0.11 & $-0.47^{* *}$ & $-0.70^{* *}$ & $0.69^{* *}$ & $0.44^{* *}$ \\
\hline HK & -0.07 & $\times$ & $-0.75^{* *}$ & $-0.80^{* *}$ & -0.24 & $-0.39^{* *}$ & $-0.31^{*}$ & $0.69^{* *}$ & $0.90^{* *}$ & $-0.85^{* *}$ & $-0.89^{* *}$ \\
\hline IDN & -0.08 & -0.09 & $\times$ & $0.86^{* *}$ & 0.24 & $0.84^{* *}$ & 0.29 & $-0.80^{* *}$ & $-0.91^{* *}$ & $0.96^{* *}$ & $0.81^{* *}$ \\
\hline JPN & -0.03 & 0.04 & -0.00 & $\times$ & 0.17 & $0.59^{* *}$ & $0.47^{* *}$ & $-0.73^{* *}$ & $-0.88^{* *}$ & $0.89^{* *}$ & $0.91^{* *}$ \\
\hline KOR & -0.06 & -0.10 & 0.06 & -0.04 & $\times$ & $0.46^{* *}$ & 0.14 & 0.17 & -0.11 & 0.13 & 0.20 \\
\hline MAL & 0.03 & $-0.25^{*}$ & $0.23^{*}$ & -0.07 & $0.24^{*}$ & $\times$ & 0.15 & $-0.42^{* *}$ & $-0.58^{* *}$ & $0.68^{* *}$ & $0.49^{* *}$ \\
\hline NZL & 0.16 & -0.19 & 0.16 & 0.03 & 0.13 & $0.30^{* *}$ & $\times$ & -0.18 & $-0.35^{*}$ & $0.32^{*}$ & 0.21 \\
\hline PLP & $-0.21^{*}$ & -0.06 & 0.04 & 0.10 & 0.10 & $0.26^{* *}$ & 0.12 & $\times$ & $0.83^{* *}$ & $-0.86^{* *}$ & $-0.77^{* *}$ \\
\hline SGP & -0.01 & 0.08 & -0.07 & -0.08 & -0.01 & $0.22^{*}$ & 0.16 & $0.19^{*}$ & $\times$ & $-0.99^{* *}$ & $-0.85^{* *}$ \\
\hline THL & 0.11 & 0.06 & -0.11 & 0.13 & 0.11 & 0.06 & -0.11 & 0.15 & 0.19 & $\times$ & $0.86^{* *}$ \\
\hline TWN & 0.04 & -0.01 & 0.11 & $-0.26^{* *}$ & -0.15 & 0.07 & -0.04 & 0.06 & $0.30^{* *}$ & 0.22 & $\times$ \\
\hline & \multicolumn{8}{|c|}{$, *:$ significant at $5 \%$ respectively $10 \%$ level } & & \\
\hline
\end{tabular}

Table 7: Correlations among investment shocks (lower left) and responses (upper right) 
of 0.60 ; significantly lower values could at most be detected for Hong Kong and the Philippines. Though, the interpretation should take into account, that the zero long-run restrictions naturally contribute to high impulse response correlations.

\begin{tabular}{|c|c|c|c|c|c|c|c|c|c|c|c|}
\hline & AUS & HK & IDN & JPN & KOR & MAL & NZL & PLP & SGP & THL & TWN \\
\hline AUS & $\times$ & $0.44^{* *}$ & $0.91^{* *}$ & $0.92^{* *}$ & $0.78^{* *}$ & $0.91^{* *}$ & $0.71^{* *}$ & $0.50^{* *}$ & $0.73^{* *}$ & $0.90^{* *}$ & $0.63^{* *}$ \\
\hline HK & 0.10 & $\times$ & $0.40^{* *}$ & $0.32^{*}$ & $0.51^{* *}$ & $0.53^{* *}$ & $0.81^{* *}$ & -0.23 & $0.32^{*}$ & $0.40^{* *}$ & $0.65^{* *}$ \\
\hline IDN & -0.06 & -0.11 & $\times$ & $0.72^{* *}$ & $0.88^{* *}$ & $0.77^{* *}$ & $0.59^{* *}$ & $0.51^{* *}$ & $0.94^{* *}$ & $1.00^{* *}$ & $0.66^{* *}$ \\
\hline JPN & -0.05 & 0.15 & -0.03 & $\times$ & $0.58^{* *}$ & $0.85^{* *}$ & $0.69^{* *}$ & $0.45^{* *}$ & $0.49^{* *}$ & $0.69^{* *}$ & $0.53^{* *}$ \\
\hline KOR & 0.09 & 0.10 & $0.22^{*}$ & 0.12 & $\times$ & $0.78^{* *}$ & $0.64^{* *}$ & 0.18 & $0.82^{* *}$ & $0.88^{* *}$ & $0.54^{* *}$ \\
\hline MAL & -0.02 & 0.17 & -0.13 & $-0.22^{*}$ & -0.10 & $\times$ & $0.73^{* *}$ & 0.17 & $0.53^{* *}$ & $0.76^{* *}$ & $0.48^{* *}$ \\
\hline NZL & 0.17 & $0.22^{*}$ & 0.01 & $0.20^{*}$ & 0.18 & 0.04 & $\times$ & 0.05 & $0.43^{* *}$ & $0.58^{* *}$ & $0.74^{* *}$ \\
\hline PLP & -0.02 & -0.02 & $-0.23^{*}$ & 0.12 & $0.23^{* *}$ & $-0.14^{*}$ & $0.20^{*}$ & $\times$ & $0.48^{* *}$ & $0.50^{* *}$ & 0.19 \\
\hline SGP & 0.08 & -0.06 & -0.12 & -0.10 & -0.11 & 0.09 & -0.05 & 0.11 & $\times$ & $0.95^{* *}$ & $0.68^{* *}$ \\
\hline THL & -0.05 & 0.03 & -0.19 & $-0.24^{*}$ & 0.04 & 0.05 & 0.19 & 0.20 & 0.04 & $\times$ & $0.66^{* *}$ \\
\hline TWN & 0.07 & $0.34^{* *}$ & -0.10 & 0.11 & 0.15 & 0.11 & $0.35^{* *}$ & $0.17^{*}$ & -0.08 & -0.02 & $\times$ \\
\hline & \multicolumn{8}{|c|}{$,{ }^{*}:$ significant at $5 \%$ respectively $10 \%$} & level & & \\
\hline
\end{tabular}

Table 8: Correlations among demand shocks (lower left) and responses (upper right)

\subsection{Explaining Shocks}

In continuation, I aim at finding evidence for connections between important modelexogenous macro variables and the identified structural shocks. This is done by accumulating the shocks, thus producing random walk or stochastic trend series, and then testing for cointegration. As these trends do not contain level and trend shifts, which have been explicitly considered in the underlying model deterministics, corresponding breaks in the additional series are taken into account in the trace tests. ${ }^{8}$ In most cases, the additional series prove to be weakly exogenous, thus "explaining" variables. Nonetheless, in view of the interdependences in a (growing) economic system, the finding of several feedback relations comes not as a surprise.

For explaining export shocks, intuitive candidates are foreign incomes and exchange rates. Table 9 shows the p-values of the trace tests between the respective export trends and the real per capita GDPs of Japan, Euroland (Eurostat, seasonally adjusted, starting 1980) and the USA (Dept. of Commerce), as well as the real effective exchange rates

\footnotetext{
${ }^{8}$ The exact specifications including the lag lengths are available from the author upon request.
} 
(J.P. Morgan). ${ }^{9}$ Summarising the figures, export trends are determined by the US GDP, followed by Euroland and Japan. Indonesia, Malaysia and Thailand yield the weakest evidence. Furthermore, the exchange rates exhibit the closest connections to the exports of the smaller or currently not matured economies.

\begin{tabular}{|c|c|c|c|c|c|c|c|c|c|c|c|}
\hline & AUS & HK & IDN & JPN & KOR & MAL & NZL & PLP & SGP & THL & TWN \\
\hline JPN & 0.23 & 0.02 & 0.16 & - & 0.03 & 0.16 & 0.04 & 0.41 & 0.23 & 0.57 & 0.61 \\
\hline Euro & 0.23 & 0.09 & 0.82 & 0.07 & 0.06 & 0.31 & 0.14 & 0.06 & 0.19 & 0.78 & 0.15 \\
\hline USA & 0.07 & 0.12 & 0.28 & 0.00 & 0.00 & 0.57 & 0.01 & 0.02 & 0.06 & 0.56 & 0.02 \\
\hline REER & 0.89 & 0.03 & I $(0)$ & 0.86 & 0.20 & 0.00 & 0.09 & I $(0)$ & 0.16 & I $(0)$ & 0.02 \\
\hline
\end{tabular}

Table 9: Trace test p-values: export trends vs. foreign incomes resp. exchange rates

Capital formation is likely to depend on profit expectations, here represented by the indexed share prices from the main national stock exchanges, and interest rates as opportunity costs (long-term government bond yields or similar rates if not available). Interpreting Table 10 reveals the strong connection of investment with share prices in most industrialised countries. The contrary result for Hong Kong is not curious, because its extreme openness and its role as an international stock market could disconnect the Hang Seng from domestic investment; see as well the wrong-directed adjustment in Table 3. Since national stock markets are likely to follow strong idiosyncratic determinants, the weak relations between the investment shocks (Table 7) do not come as a surprise. The linkage between capital formation and bond yields is relatively well developed. In Japan, it has probably weakened during the long deflationary period marked by ineffective interest rate lowering, and Singapore is known not relying on bond financing.

\begin{tabular}{|c|c|c|c|c|c|c|c|c|c|c|c|}
\hline & AUS & HK & IDN & JPN & KOR & MAL & NZL & PLP & SGP & THL & TWN \\
\hline share & 0.06 & 0.63 & 0.01 & 0.00 & 0.06 & 0.01 & 0.00 & 0.47 & 0.04 & 0.34 & 0.77 \\
\hline interest & 0.06 & 0.06 & 0.00 & 0.46 & 0.03 & 0.34 & 0.11 & 0.10 & 0.93 & 0.02 & 0.83 \\
\hline
\end{tabular}

Table 10: Trace test p-values: investment trends vs. share prices resp. interest rates

Addressing the aggregate demand shocks, compelling explanatory power can be expected in the main macroeconomic policy variables, public expenditure (per capita real government consumption) and money (per capita real M3; M2 where not available). Indeed, for most countries at least one of the tests in Table 11 is in favour of cointegration. Bearing in mind the demand correlation cluster from Table 8, the interpretation of a relatively

\footnotetext{
${ }^{9}$ In case of stationarity, no p-value is reported.
} 
consistent macroeconomic policy among the industrialised countries seems to be appealing. The remaining variation is left to be explained by other sources, probably private aggregate demand.

\begin{tabular}{|c|c|c|c|c|c|c|c|c|c|c|c|}
\hline & AUS & HK & IDN & JPN & KOR & MAL & NZL & PLP & SGP & THL & TWN \\
\hline G & 0.03 & 0.18 & 0.01 & 0.08 & 0.10 & 0.28 & 0.08 & 0.04 & 0.42 & 0.09 & 0.83 \\
\hline M3 & 0.62 & 0.03 & 0.01 & 0.61 & $\mathrm{I}(0)$ & 0.36 & 0.03 & $\mathrm{I}(0)$ & 0.08 & 0.25 & 0.43 \\
\hline
\end{tabular}

Table 11: Trace test p-values: demand trends vs. government consumption resp. M3

\section{Concluding Summary}

Guided by the task to shed light on the Asian Pacific economic growth process, this paper focused on the role of exports and investment. Integrating these variables together with GDP in cointegrating systems led to estimations of dynamic impacts, which underlie the impressive economic development. Furthermore, the explicit identification of the structural shocks allowed to compare and explain the major driving forces of the different economies in an aspiring region.

In all considered countries, the three-dimensional systems of GDP, exports and gross fixed capital formation contain two common stochastic trends. The cointegrating vectors and the highly significant GDP adjustment parameters supported the hypothesis, that one export and one investment trend drive the income growth dynamics. On the one hand, this is consistent with the export-led growth hypothesis, which has especially gained relevance in the South-East Asian industrialisation, while on the other hand, it underpins the crucial importance of capital accumulation for economic progress.

Imposing short- and long-run restrictions allowed the identification of two persistent growth shocks as well as one transitory demand shock. In almost all cases, the former have a positive and significant effect on the long-run GDP level. Apart from that, the demand shocks initiate positive GDP effects with sensible durations.

Subsequently, economic coherence in the Asian Pacific region has been analysed. Addressing the similarity of structural innovations, I correlated the respective shock time series. While the investment shocks exhibit strong idiosyncratic components, I was able to identify clusters of countries subject to resembling export and demand disturbances. With this investigation directing at the pure presence of related shocks, the question of symmetric reactions can be incorporated by correlating the impulse responses. These 
calculations yielded a high degree of symmetry, but also a few interesting exceptions concerning above all Hong Kong, the Philippines and Japan.

In order to uncover systematic connections of the structural trends, in the last step, I tested for cointegration with several macroeconomic variables. In particular, export trends seem to be largely determined by exchange rates and foreign income. In this, the USA proved to be slightly more important than Euroland and Japan. For investment and demand shocks, significant cointegration could be frequently established with share price and interest rates, respectively government consumption and money.

In an attempt to grasp the "Asian miracle" of powerful economic growth, two major sources come to the fore within a mixture of impulses from the outside industrialised world as well as domestic dynamics, in fashion of exports and investments. Furthermore, several features of economic growth are shared in the Asian Pacific region. This implies, that amongst others, policies aiming at free trade, capital market deepening, transnational investment and monetary cooperation, as well as sustainable development, should be constructed along these lines. For example, one should take into account investment effects of interest rates as instruments of foreign exchange management, the importance of exports in regional and world trade liberalisation, and the role of capital stocks and flows in the building of sound domestic and international financial systems. Besides these second-step policy implications, one should be aware, that past growth trends are not to be simply extrapolated, making it necessary to continue in exhausting new potentials of progress.

\section{References}

[1] Bayoumi, T., B. Eichengreen (1994): One Money or Many? Analyzing the Prospects of Monetary Unification in Various Parts of the World. Princeton Studies in International Finance, 76.

[2] Davidson, R., J. MacKinnon (1993): Estimation and Inference in Econometrics. Oxford University Press, London.

[3] Dickey, D.A., W.A. Fuller (1979): Distribution of the Estimators for Autoregressive Time Series with a Unit Root. Journal of the American Statistical Association, 74, 427-431. 
[4] Doornik, J.A. (1998): Approximations to the asymptotic distributions of cointegration tests. Journal of Economic Surveys, 12, 573-593.

[5] Feasel, E., Y. Kim, S.C. Smith (2001): Investment, Export and Output in South Korea: A VAR Approach to Growth Empirics. Journal of Development Economics, $5,421-432$.

[6] Feder, G. (1982): On exports and economic growth. Journal of Development Economics, 12, 59-73.

[7] Gonzalo, J., S. Ng (2001): A systematic framework for analyzing the dynamic effects of permanent and transitory shocks. Journal of Economic Dynamics and Control, 25, 1527-1546.

[8] Grossman, G., E. Helpman (1991): Innovation and Growth in the Global Economy. MIT Press, Cambridge.

[9] Hall, P. (1992): The Bootstrap and Edgeworth Expansion. Springer, New York.

[10] Helpman, E., P.R. Krugman (1985): Market Structure and Foreign Trade. Cambridge, MIT Press.

[11] Johansen, S. (1994): The role of the constant and linear terms in cointegration analysis of nonstationary time series. Econometric Reviews, 13, 205-231.

[12] Johansen, S. (1995): Likelihood-based Inference in Cointegrated Vector Autoregressive Models. Oxford University Press, Oxford.

[13] Johansen, S., R. Mosconi, B. Nielsen (2000): Cointegration analysis in the presence of structural breaks in the deterministic trend. Econometrics Journal, 3, 216-249.

[14] Jones, C.I. (1995): Time Series Tests of Endogenous Growth Models. The Quaterly Journal of Economics, 110, 495-525.

[15] Kimura, F. (2006): International Production and Distribution Networks in East Asia: 18 Facts, Mechanics, and Policy Implication. Asian Economic Policy Review, forthcoming.

[16] Krishna, K., A. Ozyildirim, N.R. Swanson (1998): Trade, Investment, and Growth: Nexus, Analysis, and Prognosis. NBER Working Paper 6861, National Bureau of Economic Research. 
[17] Krueger, A.O. (1985): The experience and lessons of Asia's super exporters. In Corbo, V., A.O. Krueger, F. Ossa (eds): Export-oriented Development Strategies: the success of five newly industrializing countries. Boulder/London, West View Press, 187212.

[18] Krugman, P. (1994): The Myth of Asia's Miracle. Foreign Affairs, 73, 62-78.

[19] Lanne, M., H. Lütkepohl, P. Saikonen (2002): Comparison of unit root tests for time series with level shifts. Journal of time series analysis, 23, 667-685.

[20] Lewis, W.A. (1980): The Slowing Down of the Engine of Growth. American Economic Review, 70, 555-564.

[21] Lucas, R.E. (1988): On the Mechanics of Economic Development. Journal of Monetary Economics, 22, 3-42.

[22] Nelson, R.R., H. Pack (1999): The Asian Miracle and Modern Growth Theory. Economic Journal, 109, 416-436.

[23] Perron, P. (1989): The great crash, the oil price shock and the unit root hypothesis. Econometrica, 57, 1361-401.

[24] Rodrigo, G.C. (2000): East Asia's Growth: Technology or Accumulation? Contemporary Economic Policy, 18, 215-227.

[25] Romer, P.M. (1986): Increasing Returns and Long-Run Growth. Journal of Political Economy, 94, 1002-37.

[26] Saikkonen, P., H. Lütkepohl ( 2002): Testing for a unit root in a time series with a level shift at unknown time. Econometric Theory, 18, 313-348.

[27] Solow, R. (1956): A Contribution to the Theory of Economic Growth. Quarterly Journal of Economics, 70, 65-94.

[28] Solow, R. (1960): Investment and Technical Progress. In Arrow, K., S. Karlin, P. Suppes (eds): Mathematical Methods in the Social Sciences. Stanford, 89-104.

[29] Trenkler, C. (2004): Determining p-values for systems cointegration tests with a prior adjustment for deterministic terms. CASE Discussion Paper 37, HumboldtUniversität zu Berlin. 


\section{Appendix}

\begin{tabular}{|c|c|c|c|c|c|c|c|c|c|}
\hline & EXP & lags & shifts & GCF & lags & breaks & GDP & lags & breaks \\
\hline AUS & -1.61 & 4 & & -0.30 & 5 & & -0.80 & 4 & \\
\hline HK & -1.87 & 6 & $00: 3 \mathrm{~T}$ & -1.87 & 7 & $98: 1$ & -2.34 & 8 & $98: 1$ \\
\hline IDN & -2.98 & 0 & & -0.74 & 0 & $98: 2$ & -2.58 & 5 & $98: 2$ \\
\hline JPN & 0.99 & 5 & & -1.91 & 8 & & -1.63 & 4 & \\
\hline KOR & 1.33 & 9 & & -0.93 & 3 & $98: 1$ & -0.84 & 4 & $98: 1$ \\
\hline MAL & -2.24 & 1 & $01: 2 \mathrm{~L}$ & -1.95 & 1 & $98: 1$ & -2.00 & 1 & $98: 1$ \\
\hline NZL & -3.08 & 6 & & -2.19 & 0 & $91: 1$ & -2.17 & 4 & $91: 1$ \\
\hline PLP & -1.20 & 4 & $98: 1 \mathrm{~L}, 86: 1 \mathrm{~T}$ & -2.50 & 5 & $84: 3$ & -2.73 & 4 & $84: 3$ \\
\hline SGP & -0.67 & 1 & & -2.10 & 1 & $85: 2$ L, $98: 1 \mathrm{~T}$ & -2.86 & 1 & \\
\hline THL & -2.51 & 0 & & -1.37 & 0 & $98: 1$ & -1.93 & 4 & $98: 1$ \\
\hline TWN & 0.85 & 5 & & -1.31 & 6 & $01: 1$ & -1.28 & 8 & $01: 1$ \\
\hline \multicolumn{7}{|c|}{$* H_{0}$ can be rejected at $10 \%$ significance level } \\
constant, trend and seasonal dummies included; L: level shift, T: trend shift \\
\hline
\end{tabular}

Table 12: Unit root test statistics

\begin{tabular}{|c|c|c|c|c|}
\hline & lags & shifts & impulse dummies & remarks \\
\hline AUS & 3 & & $00: 3,00: 4,97: 2$ & \\
\hline HK & 6 & $98: 1,00: 3$ & $85: 2,98: 3$ & $00: 3$ trend shift \\
\hline IDN & 1 & & $98: 2,00: 1$ & no trend \\
\hline JPN & 5 & $91: 4$ & $93: 2,94: 1,98: 1$ & $91: 4$ trend shift \\
\hline KOR & 6 & & $97: 2,98: 1,03: 3,03: 4,05: 3$ & \\
\hline MAL & 0 & & $95: 3,95: 4,98: 1$ & \\
\hline NZL & 4 & $91: 1$ & $91: 1,98: 2$ & \\
\hline PLP & 4 & & $88: 4,98: 1,98: 2,98: 4$ & no constant \\
\hline SGP & 1 & & $94: 2,98: 1,02: 3,03: 2,03: 3,05: 1$ & \\
\hline THL & 2 & & $97: 1,97: 4,01: 1$ & no trend \\
\hline TWN & 5 & & $00: 2,00: 4,03: 3,05: 4$ & 2-step estimation \\
\hline
\end{tabular}

Table 13: VECM specifications 

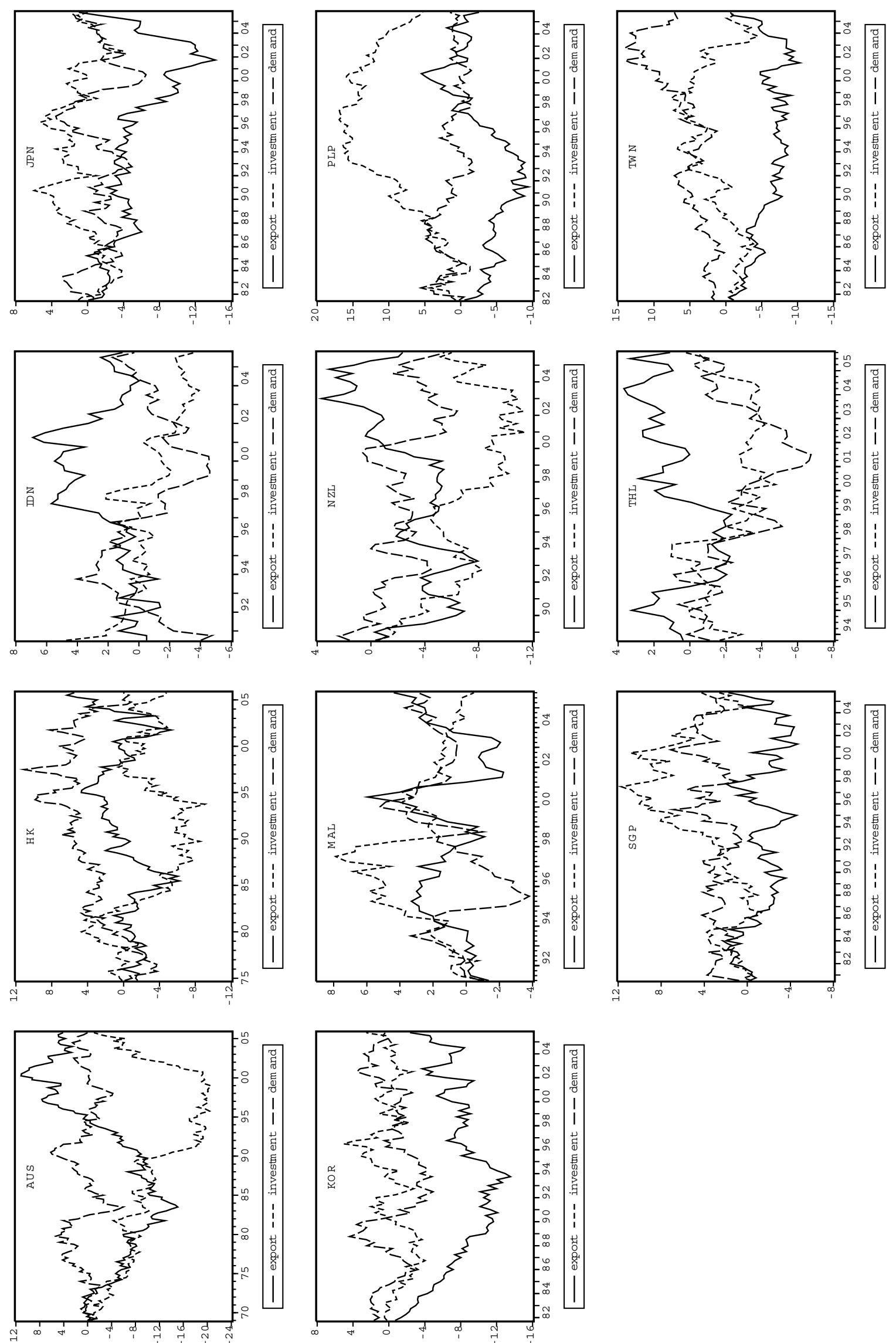

Figure 2: Accumulated structural shocks (in 2002 p.c. PPP US \$) 

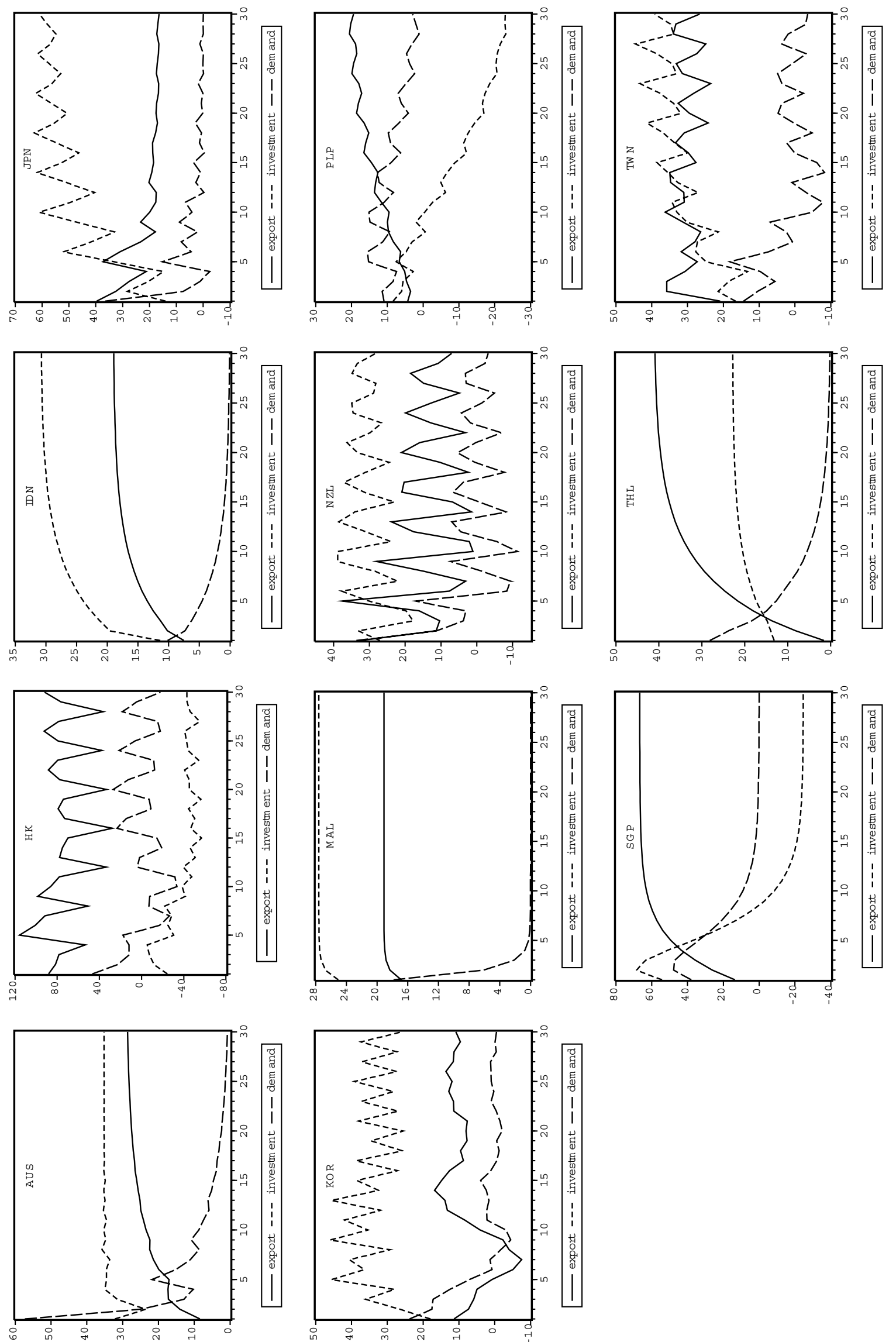

Figure 3: Impulse responses of GDP to structural unit shocks (in 2002 p.c. PPP US \$) 